\title{
PENINGKATAN KUALITAS BELAJAR DALAM MENGHADAPI PEMBELAJARAN DARING
}

\author{
Enny Irawaty ${ }^{1}$, Evelin Maharani Widjaja ${ }^{2}$, Juliana Sanjaya ${ }^{3}$ \\ ${ }^{1}$ Bagian Fisiologi , Fakultas Kedokteran, Universitas Tarumanagara Jakarta \\ Email: ennyi@fk.untar.ac.id \\ ${ }^{2}$ Mahasiswa Fakultas Kedokteran Universitas Tarumanagara Jakarta \\ Email: evelin.405180002@stu.untar.ac.id \\ ${ }^{3}$ Mahasiswa Fakultas Kedokteran Universitas Tarumanagara Jakarta \\ Email: juliana.405180128@stu.untar.ac.id
}

\begin{abstract}
Online learning methods utilize technology as an intermediary medium between teachers and teaching participants that can be done by not face to face, using computer media or gadgets based on the internet network. Online learning methods cause learners difficulty in receiving information and concepts of lecture materials. Students have no enthusiasm in learning, avoid classes, do not participate in classroom activities, and have poor learning outcomes. To foster motivation and increase academic self efficacy of students, we conduct extension activities with effective learning tips during online learning. This activity aims to increase interest, student ability so that students can adapt to the learning process and satisfactory academic achievement during counseling lectures related to information about improving the quality of learning with effective online learning tips that were held on November 7, 2021 and attended by 31 participants can be carried out properly. There is an increase in knowledge of 20.3\% this can be seen from the average results of pretes and postes values, namely 60.6 to 72.9. Effective online learning tips extension activities can be developed for further extension because the form to improve the quality of student learning is especially needed during this pandemic, because many learning activities are done at home.
\end{abstract}

Keywords: online learing, education, effective learning

\begin{abstract}
ABSTRAK
Metode pembelajaran daring memanfaatkan teknologi sebagai media perantara antara pengajar dan peserta ajar yang dapat dilakukan dengan tidak bertatap muka langsung, menggunakan media komputer atau gadget berbasis pada jaringan internet. Metode pembelajaran daring menyebabkan peserta didik kesulitan dalam menerima informasi serta konsep materi perkuliahan. Mahasiswa tidak memiliki antusias dalam belajar, menghindari kelas, tidak berpartisipasi dalam kegiatan di kelas, dan memiliki hasil belajar yang buruk. Untuk menumbuhkan motivasi dan meningkatkan academic self efficacy mahasiswa maka kami melakukan kegiatan penyuluhan dengan materi kiat belajar efektif selama pembelajaran daring. Kegiatan ini bertujuan untuk meningkatkan minat, kemampuan mahasiswa agar mahasiswa dapat beradaptasi dalam proses pembelajaran serta prestasi akademik yang memuaskan selama perkuliahan Penyuluhan terkait informasi tentang peningkatan kualitas belajar dengan tips efektif belajar secara daring yang dilaksanakan 7 November 2021 dan dihadiri 31 peserta dapat terlaksana dengan baik. Terjadi peningkatan pengetahuan sebesar $20.3 \%$ ini dapat dilihat dari hasil rata-rata nilai pretes dan postes yaitu 60.6 menjadi 72.9. Kegiatan penyuluhan tips efektif belajar secara daring dapat dikembangkan untuk penyuluhan selanjutnya karena bentuk untuk meningkatkan kualitas belajar mahasiswa/i terutama sangat dibutuhkan pada masa pandemi ini, dikarenakan banyak kegiatan pembelajaran dikerjakan di rumah.
\end{abstract}

Kata kunci: daring, edukasi, pembelajaran

\section{PENDAHULUAN}

Pendidikan yang tinggi dan kompeten dalam bidangnya merupakan faktor utama sehingga seseorang dapat mencapai kesuksesan dalam menghadapi tantangan hidup (Shkullaku, 2013). Perguruan Tinggi diharapkan mampu menciptakan suasana belajar yang harmonis sehingga mahasiswanya merasa nyaman serta dapat belajar dengan baik sehingga mampu menghadapi perkembangan ilmu. (Dewi \& Sudiantara, 2015).

Dalam kegiatan pembelajaran mahasiswa harus mampu beradaptasi dengan proses belajarnya di Perguruan Tinggi karena perbedaan pola pembelajaran saat sekolah menengah. Mahasiswa yang 
mampu beradaptasi dengan baik terhadap pola pembelajaran di perguruan tinggi membuat kegiatan akademik berjalan dengan baik (Arlinkasari \& Akmal, 2017). Pemicu terjadinya kelelahan baik secara fisik dan mental pada mahasiswa karena tugas akademik yang banyak selain itu stress akibat kegiatan non akademik turut berperan serta membuat beban pada mahasiswa. (Fernandez-Castillo, 2021).

Pembelajaran di perkuliahan menggunakan metode online disebabkan pandemi berkepanjangan dan mahasiswa dituntut untuk beradaptasi terhadap metode pembelajaran online. (Kemendikbud, 2020; Mustofa, 2020). Kesulitan memahami serta tuntutan tugas yang banyak diberikan secara online membuat mahasiswa terbebani dalam pembelajarannya. (Asikainen et al., 2020). Berdasarkan rangkuman terhadap temuan penelitian di berbagai jenjang dan jenis pendidikan, baik di dalam dan luar negeri, Hariko $(2020,2021)$ menyimpulkan bahwa siswa dan mahasiswa mengalami hambatan akibat berbagai kelemahan pelaksanaan pembelajaran daring. Metode pembelajaran dengan sistem tatap muka lebih diminati siswa dan mahasiswa dibandingkan pembelajaran daring.

Metode pembelajaran daring berpengaruh terhadap proses perkuliahan menjadi tidak maksimal, seperti: mahasiswa sering menunda-nunda tugas, mahasiswa mengerjakan tugas apa adanya, dan kurangnya minat belajar dalam belajar kondisi ini berpengaruh prestasi belajar. (Khatami, 2018; Lim et al., 2020; Wang et al., 2020).

Hasil survei dilapangan menunjukkan mahasiswa banyak mengalami saat belajar dilakukan secara online. Terjadinya pergeseran pola pembelajaran membuat tekanan serta beban bagi mahasiswa dalam proses pembelajarannya. Beradasarkan permasalahan tersebut tim pengabdian bermaksud melakukan kegiatan penyuluhan terkait upaya peningkatan kualitas belajar selamam pembelajaran online.

\section{METODE PELAKSANAAN}

Kegiatan penyuluhan Peningkatan Kualitas Belajar Dalam Menghadapi Pembelajaran Daring terutama di pandemi COVID-19 yang berkepanjangan dilakukan bertujuan untuk memberikan edukasi terkait adaptasi cara pembelajaran secara daring terutama disertai menghadapi pandemi COVID-19 berkepanjangan. Target dari kegiatan ini adalah dewasa muda khususnya mahasiswa terutama mahasiswa yang baru mengikuti perkuliahan. Persiapan yang dilakukan oleh tim pengabdian adalah rapat internal untuk menyiapkan materi kegiatan PKM, proses penyuluhan dan tanya jawab. Tim pengabdian membuat kuesioner penilaian dengan memberikan pretest dan post test. Pretest yang disebarkan sebelum penyampaian materi untuk menilai pengetahuan dasar peserta pengadian terkait materi yang disampaiakan. Postest dilakukan setelah pemaparan materi untuk menilai tingkat pengetahuan setelah mengikuti penyuluhan.

\section{HASIL DAN PEMBAHASAN}

Sebelum kegiatan bakti kesehatan dilaksanakan, tim melakukan rapat persiapan terlebih dahulu. Kegiatan persiapan meliputi: penentuan topik berdasarkan masalah dan permintaan dari masyarakat, penentuan tim, pembuatan proposal hingga penyampaikan rencana kepada pidak di lokasi tempat kegiatan bakti kesehatan akan dilaksanakan. Rapat persiapan pertama telah dilaksanakan pada tanggal 15 Oktober 2021. Dalam rapat tersebut, tim membahas mengenai rencana waktu pelaksanaan, persiapan pretes dan postes hingga games yang akan dilakukan biar peserta tidak merasa bosan, hanya mendengar penyuluhan saja. Tim kemudian menentukan waktu pelaksanaan kegiatan bakti kesehatan akan dilaksanakan pada tanggal 7 November 2021, mulai pukul 13.00-15.00 WIB dengan mempertimbangkan calon peserta tidak ada kegiatan pembelajaran di hari tersebut. Tim juga hasil rapat disepakati bahwa pelaksanaan kegiatan bakti kesehatan akan dilaksanakan pada merencanakan akan melakukan rapat persiapan kedua padata tanggl 2 November 2021 sebagai persiapan akhir sebelum pelaksanaan kegiatan bakti kesehatan. 


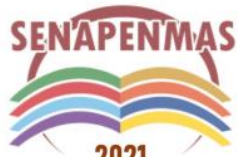

2021
Seminar Nasional Hasil Penelitian dan Pengabdian Kepada Masyarakat 2021

Pengembangan Ekonomi Bangsa Melalui Inovasi Digital Hasil Penelitian dan Pengabdian Kepada Masyarakat Jakarta, 21 Oktober 2021

Kegiatan bakti kesehatan dilaksanakan pada tanggal 07 November 2021 secara daring dengan menggunakan aplikasi zoom meeting. Kegiatan dimulai pada pukul 13.00 WIB diawali dengan pembukaan dan peserta diminta untuk mengisi pretes terlebih dahulu, acara kegiatam dapat dilihat pada tabel 1. Pada gambar 2 dapat dilihat peningkatan kualitas belajar daring melalui tips pembelajaran efektif dipaparkan oleh dr Enny Irawati, MPdKed dengan tujuan mahasiswa dapat termotivasi untuk belajar dengan efektif, serta mampu beradaptasi dengan kegiatan perkuliahan daring. Manfaat dari kegiatan ini bertambah kesadaran dan semangat belajar serta wawasan dalam kiat proses pembelajaran yang efektif selama pembelajaran daring. Kedisiplinan dalam menerapkan prinsip kiat pembelajaran dengan baik mendorong mahasiswa/idapat beradaptasi diperkuliahan dan merupakan kunci untuk mencapai prestasi akademik yang berkualitas baik.

Tabel 1. Susunan acara kegiatan

\begin{tabular}{lll}
\hline Waktu & Topik & Pembicara \\
\hline $12.15-12.40$ & Registrasi & Panitia \\
\hline $12.40-12.45$ & Pembukaan & Panitia \\
\hline $12.45-13.00$ & Pre Tes & Panitia \\
\hline $13.00-13.30$ & Peningkatan kualitas belajar & Tim Bakti Kesehatan dr. Enny \\
\hline $13.30-13.45$ & Games & \\
\hline $13.45-14.30$ & Tanya Jawab & \\
\hline $14.30-15.00$ & Penutupan dan Postes & \\
\hline
\end{tabular}

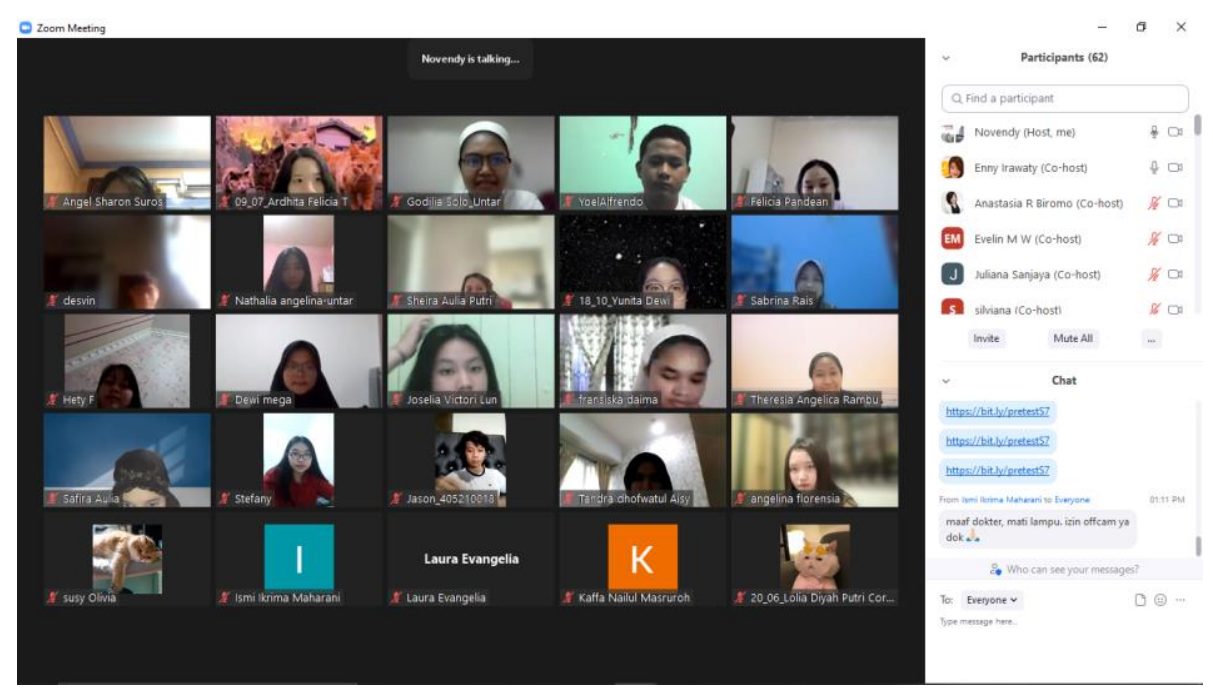

Gambar 1.

Dokumentasi kegiatan penyuluhan tips efektif belajar daring 


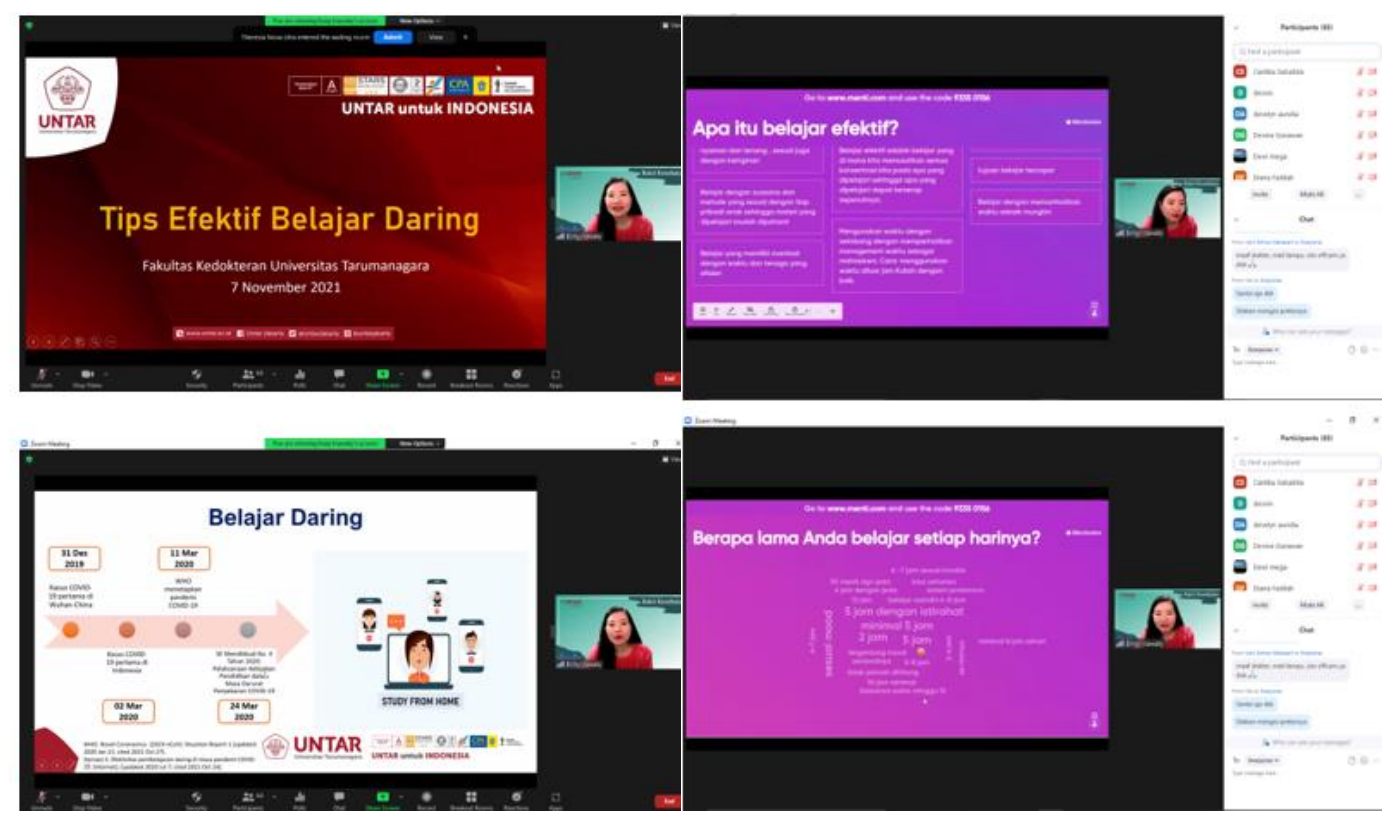

Gambar 2

Kegiatan penyuluhan materi tips efektif belajar daring

Kegiatan penyuluhan tentang tips efektif belajar daring dihadiri oleh 31 peserta dengan rata-rata usia peserta penyuluhan adalah 18.5 tahun dengan rentang usia antara $17-26$ tahun. Dari 31 peserta yang mengikuti kegiatan penyuluhan sebanyak $8(25.8 \%)$ peserta berjenis kelamin lakilaki dan 23 (74.2\%) peserta berjenis kelamin perempuan. Pada gambar 2 dapat dilihat hasil ratarata pretest sebesar 60.6 meningkat menjadi 72.9 pada hasil postest, maka terjadi peningkatan pengetahuan sebesar $20.3 \%$ ini dapat dilihat dari hasil rata-rata nilai pretes dan postes. Dengan peningkatan pengetahuan ini diharapkan peserta penyuluhan bertambah wawasan tentang belajar efektif selama proses daring dan peserta penyuluhan dapat menerapkan belajar efektif dalam kegiatan pembelajaran sehari-hari

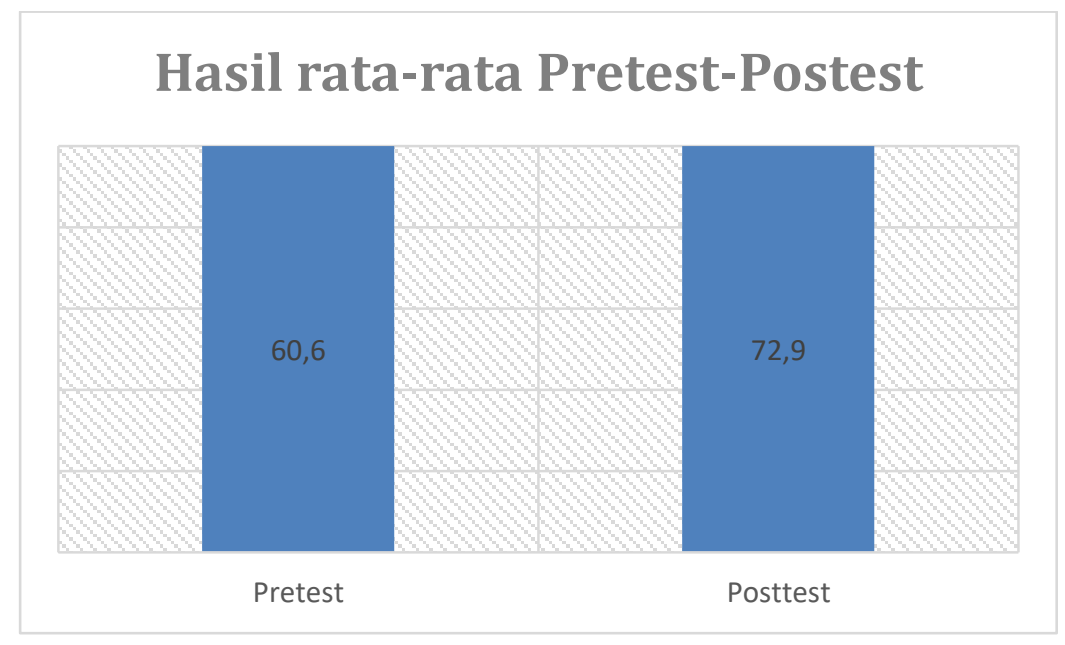

Gambar 3

Hasil rata-rata pretest-postest 


\section{KESIMPULAN DAN SARAN}

Penyuluhan terkait informasi tentang peningkatan kualitas belajar dengan tips efektif belajar secara daring yang dilaksanakan 7 November 2021 dan dihadiri 31 peserta dapat terlaksana dengan baik. Terjadi peningkatan pengetahuan sebesar $20.3 \%$ ini dapat dilihat dari hasil rata-rata nilai pretes dan postes yaitu 60.6 menjadi 72.9. Kegiatan penyuluhan tips efektif belajar secara daring dapat dikembangkan untuk penyuluhan selanjutnya karena bentuk untuk meningkatkan kualitas belajar mahasiswa/i terutama sangat dibutuhkan pada masa pandemi ini, dikarenakan banyak kegiatan pembelajaran dikerjakan di rumah.

\section{Ucapan Terima Kasih}

Penulis PKM mengucapkan terima kasih kepada Rektor Universitas Tarumanagara beserta jajaran, Lembaga Penelitian dan Pengabdian Masyarakat Univeristas Tarumanagara atas pendanaan sehingga kegiatan pengabdian kepada masyarakat dapat terlaksana. Penulis juga mengucapkan terima kasih kepada Pimpinan Fakultas Kedokteran Universitas Tarumanagara beserta jajaran atas dukungannya dalam pelaksanaan kegiatan PKM ini. Terima kasih kepada peserta PKM atas dukungan dan partisipasinya dalam kegiatan ini. Terima kasih kepada Panitia SENAPENMAS yang memberikan kesempatan sehingga dapat berpatisipasi pada kegiatan SENAPENMAS 2021

\section{REFERENSI}

Arlinkasari, F.\& Akmal, S. Z. (2017). Hubungan Antara School Engagement, Academic Self - Efficacy Dan Academic Burnout Pada Mahasiswa. Humanitas (Jurnal Psikologi), 1(2), 81-102. https://doi.org/10.28932/humanitas.v1i2.418

Asikainen, H., Salmela-Aro, K., Parpala, A., \& Katajavuori, N. (2020). Learning profiles and their relation to study-related burnout and academic achievement among university students. Learning and Individual Differences, 78, 101781. https://researchportal.helsinki.fi/en/publications/learning-profiles-and-their-relation-tostudy-related-burnout-and-2

Dewi, N. P., \& Sudiantara, Y. (2015). Hubungan Self Efficacy Dengan Prokrastinasi Akademik Pada Mahasiswa Fakultas Psikologi Kurikulum Berbasis Kompetensi Unika Soegijapranata Semarang. Psikodimensia, 14(2), 96-104. http://journal.unika.ac.id/index.php/psi/article/view/974

Fernandez-Castillo, A. (2021). State-anxiety and academic burnout regarding university access selective examinations in spain during and after the covid-19 lockdown. Frontier in Psychology, 12. https://doi.org/10.3389/fpsyg.2021.621863

Hariko, R. (2020). Pengembangan Model Bimbingan Kelompok Agentik untuk Meningkatkan Perilaku Prososial Siswa Sekolah Menengah Pertama. Disertasi. Universitas Negeri

Malang. https://journal.unnes.ac.id/sju/index.php/jubk/article/view/21796

Kemendikbud. (2020). Surat edaran mendikbud nomor 4 tahun 2020. http://pgdikmen.kemdikbud.go.id/read-news/surat-edaran-mendikbud-nomor-4-tahun$\underline{2020}$

Khatami, R. A. (2018). Hubungan stres terhadap burnout pada Mahasiswa preklinik fakultas kedokteran UIN Syarif Hidayatullah Jakarta tahun ajaran 2018/2019. Fakultas Kedokteran Universitas Islam Negeri Syarif Hidayatullah Jakarta https://repository.uinjkt.ac.id/dspace/bitstream/123456789/53739/1/RISA\%20AZZAH RA\%20KHATAMI\%20-\%20FK.pdf 
Lim, W. Y., Ong, J., Ong, S., Hao, Y., Abdullah, H. R., Koh, D. L. K., \& Mok, U. S. M. (2020).The abbreviated Maslach burnout inventory can overestimate burnout: a study of anesthesiology residents. Journal of Clinical Medicine, 9(1), 61. https://www.ncbi.nlm.nih.gov/pmc/articles/PMC7020051/

Wang, J., Okoli, C. T. C., He, H., Feng, F., Li, J., Zhuang, L., \& Lin, M. (2020). Factors associated with compassion satisfaction, burnout, and secondary traumatic stress among Chinese nurses in tertiary hospitals: A cross-sectional study. International Journal of Nursing Studies, 102, 103472. https://pubmed.ncbi.nlm.nih.gov/31810017/ 